Article

\title{
Sustainability and the Viable Systems Approach: Opportunities and Issues for the Governance of the Territory
}

\author{
Sergio Barile, Bernardino Quattrociocchi, Mario Calabrese (i) and Francesca Iandolo * (1) \\ Department of Management, Sapienza University, Rome 00161, Italy; sergio.barile@uniroma1.it (S.B.); \\ bernardino.quattrociocchi@uniroma1.it (B.Q.); mario.calabrese@uniroma1.it (M.C.) \\ * Correspondence: francesca.iandolo@uniroma1.it
}

Received: 22 January 2018; Accepted: 3 March 2018; Published: 13 March 2018

\begin{abstract}
The aim of this paper is to propose an approach for representing the territory as a dynamic system of intersubjective relationships that is able to guarantee not only the efficiency of the processes within organizations, but also effective results in the general context and a sustainable impact on the broader environment. This contribution is developed on the basis of the viable systems approach (vSa), which is intended as a theoretical framework for the analysis of social phenomena as well as for orienting government processes. Using this theoretical framework, the proposed approach leads to the representation of the territory as a viable system that is capable of surviving in its own context by creating value for the other entities of the context (public groups of governments, communities, investors, natural environment, future generations, non-human species), thus defining the essential conditions for a sustainable equilibrium. The consideration that social phenomena have to be analyzed by taking into account the different relations and interactions that orient the behavior of individuals and, as a consequence, their main collective manifestations, i.e., organizations, underlines the importance of shifting from a traditional reductionist approach to a systemic approach. In what follows, taking a cue from the definition of sustainability that implies a wider sharing, we provide some initial critical positions, and finally shape the useful elements that can be preparatory to the introduction of a working hypothesis that is capable of delineating a possible itinerary for the development of the territory.
\end{abstract}

Keywords: sustainability; territory; viable systems approach

\section{Introduction}

The aim of this paper is to propose an approach for representing the territory as a dynamic system of intersubjective relationships that are able to guarantee not only the efficiency of the processes within organizations, but also effective results in the overall context, and a sustainable impact on the broader environment. The contribution is developed on the basis of the viable systems approach (vSa), which is intended as a theoretical framework for the analysis of social phenomena as well as for orienting government processes.

Using this theoretical framework, the proposed approach leads to the representation of the territory as a viable system that is capable of surviving in its own context by creating value for the other entities of the contexts (public groups of governments, communities, investors, natural environment, future generations, non-human species), thus defining the essential conditions for a sustainable equilibrium [1].

The consideration that social phenomena have to be analyzed by taking into account the different relations and interactions that orient the behavior of individuals and, as a consequence, of their main 
collective manifestation, i.e., organizations, underlines the importance of shifting from a traditional reductionist approach to a systemic approach.

In what follows, taking a cue from the definition of sustainability, which implies a wider sharing, some initial critical positions are provided. From these, we are able to shape the useful elements that can be preparatory to the introduction of a working hypothesis that is capable of proposing a possible itinerary for the development of the territory.

\section{The Concept of Sustainability}

The currently and widely shared definition of sustainability derives from the one of sustainable development contained in the Brundtland Report [2] by the World Commission on Environment and Development: "The sustainable development is far from being a definitive condition of harmony, it is rather the process of changing, that the exploitation of resources, the direction of investments, the orientation of technological development and institutional changes are made consistent with the future needs as well as with the current ones". The ensuing discussion, led by specific committees, international organizations, and individual scholars, was mainly intended to integrate the synthetic initial definition within useful guidelines for practitioners that want to orientate their behaviors towards sustainability.

In this context, as expected, the inevitable consequence of wanting to compress sustainability into operational rules in an ideal direction has resulted in the definition of three dimensions that together specify sustainability:

$\checkmark$ Economic sustainability, as the ability to efficiently use the available resources to assure profitability over time;

$\checkmark$ Social sustainability, as the ability to ensure conditions of stability, democracy, participation, and justice, as well as the possibility to guarantee that human welfare conditions (safety, health, education) are equally distributed among classes and genders;

$\checkmark \quad$ Environmental sustainability, as the ability to maintain the quality and the reproducibility of the natural resources.

The intersection between the considered dimensions determines the conditions of development that can be defined as viable (environment and economic), equitable (social and economic), and bearable (environment and social). These dimensions appear to be preliminary, but are also necessary and sufficient for a full implementation of a commonly shared approach to sustainability (Figure 1).

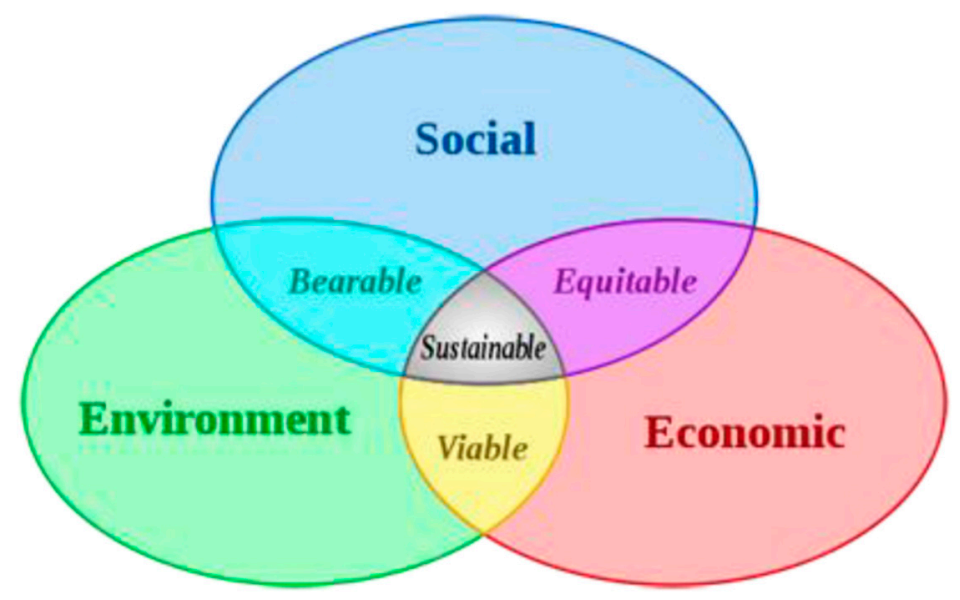

Figure 1. The three dimensions of sustainability. Source: [3], "Sustainable development" (available at http:/ / commons.wikimedia.org/wiki/File:Sustainable_development.svg).

The tripartite division above is based on Elkington's well-known triple bottom line [4], which, integrating the needs expressed by each of the three areas (people, profit, and planet), recalls the need 
to widen the perspective of business strategies and behaviors, in order to also include social equity and environmental preservation, since "the triple bottom line agenda requires companies to focus not simply on the economic value they add-or destroy" [5].

However, the resulting scheme, even if in its simplest representation, is likely to complicate rather than simplify a systemic approach to sustainability. According to the perspective of Figure 1, the intersection of the three dimensions can be seen as a sufficient condition to achieve sustainability.

In fact, it seems to be based on reflections that are mainly focused on the structure, that is, on the components and relationships, which is addressed to provide essentially quantitative requirements, and with a predominantly mechanistic character. Among these reflections, we can mention [6], who leads sustainable development back to the capacity of human beings to develop by remaining within the carrying capacity of the ecosystems, and therefore by constraining that:

$\checkmark$ the weight of human impact on natural systems does not exceed the carrying capacity of nature; $\checkmark \quad$ the utilization rate of the renewable critical resources does not exceed their regeneration rate;

$\checkmark \quad$ the emission of pollutants and waste does not surpass the absorption capacity of the environment; $\checkmark \quad$ the reduction of the non-renewable resources can be compensated by the production of an equal amount of renewable resources that are able to replace them.

The guiding principle seems to be summarized in a "mechanical" model, in which a substantial 'balance' between human actions and ecosystem reactions is expected, through a simplistic economic equation in which the periodic consumption of a given resource should not exceed its production.

However, a systemic approach to sustainability should be based on the consideration that each of the ellipses does not represent a simple sum of a set of homogeneous elements based on one or the other characteristics of belonging, but rather, each ellipse represents a configuration of a system, and, therefore, an expression of the complex network of components, relationships, and active interactions that are activated each time.

Among the systemic approaches to sustainability, [7] Robèrt was committed to giving a global definition of sustainability that implies the recovery of what he calls the system conditions, which include ecological and social aspects that are capable of putting into practice the theoretical principles of sustainable development through participatory processes. Consistently, the definition of sustainable development given by the International Council for Local Environmental Initiatives says that it involves development that provides environmental, social, and basic economic services to all of the members of a community without threatening the viability of natural and social systems, on which the provision of such services depends [8].

However, what lacks is the reference to the decision maker, which is intended as the human entity (both in individual and collective aggregations) that can orient and define the behavior of a specific system (i.e., organization).

In other words, the decision-making moment cannot be only related to the institutions and policy makers; on the contrary, in our perspective, the role of a 'subjective' interpretation of sustainability is crucial.

In this regard, in 2001, [9] United Nations Educational, Scientific and Cultural Organization (UNESCO) not surprisingly proposed to expand the concept of sustainable development, stating that "the cultural diversity is as necessary for humankind as the biodiversity is for the nature (...) Cultural diversity widens the range of options open to everyone; it is one of the roots of development, which is understood not simply in terms of economic growth, but also as a means to achieve a more satisfactory intellectual, emotional, moral, and spiritual existence" (art. 3, UNESCO Universal Declaration on Cultural Diversity).

In our opinion, what seems relevant in this proposal is not the fact that cultural diversity is considered an additional driving factor for sustainable development, but that the statement underlies a decisive and precise indication to consider the necessity of a subjective interpretation of human purposes as essential among the factors that can affect the path towards sustainability. Therefore, it 
overcomes the prevalent mechanistic approach through the introduction of a completely new element, and a reinterpretation of the context in which to search for sustainability conditions. Basically, as will be better explained in the next paragraph, in accordance with the principles of the vSa (viable systems approach), the constitutive assumptions of sustainability, and therefore, a possible discipline that permits its pursuit, must consider that the importance attributed to each of the three dimensions could be affected by subjective factors that are related to the decision makers and their strategic plan.

Considering the hypothesis of a significant influence resulting from the personal contribution of the decision makers that, in a specific time period, participate in the governance of the areas that are relevant to the purpose of sustainability, allows a redefinition of what has been previously defined as equitable, viable, and bearable. As an example, what is meant by 'bearable' usually could be affected by who is making decisions, in particular by the specific political rather than socioeconomic circumstances that affect the feasibility of one initiative or another.

This perspective can be of particular relevance in issues such as the ones related to territory government, in which decisions are taken by a variety of subjects with different roles and purposes.

\section{The Viable Systems Approach for Territory Development}

\subsection{Theoretical Framework}

Based on the previous conceptualizations, in what follows, we illustrate the guidelines for the adoption of a governance approach for territory development based on the viable systems approach (vSa).

The adoption of a systemic paradigm places emphasis on interactive and virtuous dynamics that could not occur if there were not an inclusive perspective that considers all of the actors involved in the activities of the organization $[10,11]$. In fact, "a cybernetic approach views sustainability as an ongoing process constituted through the dynamic relationships between viable organizations and the reality that these relationships lay down into their realization-in other words, as something having as much to do with context as with the organization in itself" [12].

Stafford Beer first introduced the notion of a viable system in 1972. According to this author, a system is viable if it survives, remains united, and is integral, is homeostatically balanced both internally and externally, and possesses mechanisms and opportunities for growth, learning, development, and adaptation, which allow it to become increasingly effective within its environment.

Starting from this definition, the vSa [13-15] proposes a definition of viable system that has some updates and conceptual innovations.

In fact, according to the vSa, the analysis of the structural components has to be complemented by the analysis of the dynamics that qualify a system, which are always included within a context of reference that gives the system itself the possibility of learning, adapting, and developing over time (principle of homeostasis, [13,16,17]. In fact, the ultimate purpose of a viable system is to survive within its context of reference; this purpose of survival characterizes all of the viable systems, and is reflected in the change and adaptation processes of the system's components and elements that are needed to preserve its viability.

The vSa can be defined as a systemic constructionist approach [18-24], and deals with the study of the firm included in the network of its meaningful relationships.

The approach, defined as axiomatic, is based on the following foundational principles [25]:

- Survival: a viable system has the aim to survive in a specific context;

- Eidos: from an ontological point of view, a viable system can be considered from both a structural and a systemic perspective;

- Isotropy: in terms of behavior, a viable system distinguishes an area of decision-making and one of acting;

- Acting: its aim is to reach a result, an objective, through the interaction with suprasystems and subsystems from which the system receives, but to which it also supplies indications and rules; 
- Exhaustiveness: external entities are also viable systems, and at the same time, components deriving from a superior level.

Starting from Stafford Beer's model [16,26], the vSa redefines decision and action, and identifies two specific areas in which organizations are structured: the governing body that is involved in decision-making strategies, and the operating structure that is involved in routine decisions regarding their activity (Figure 2) [15].

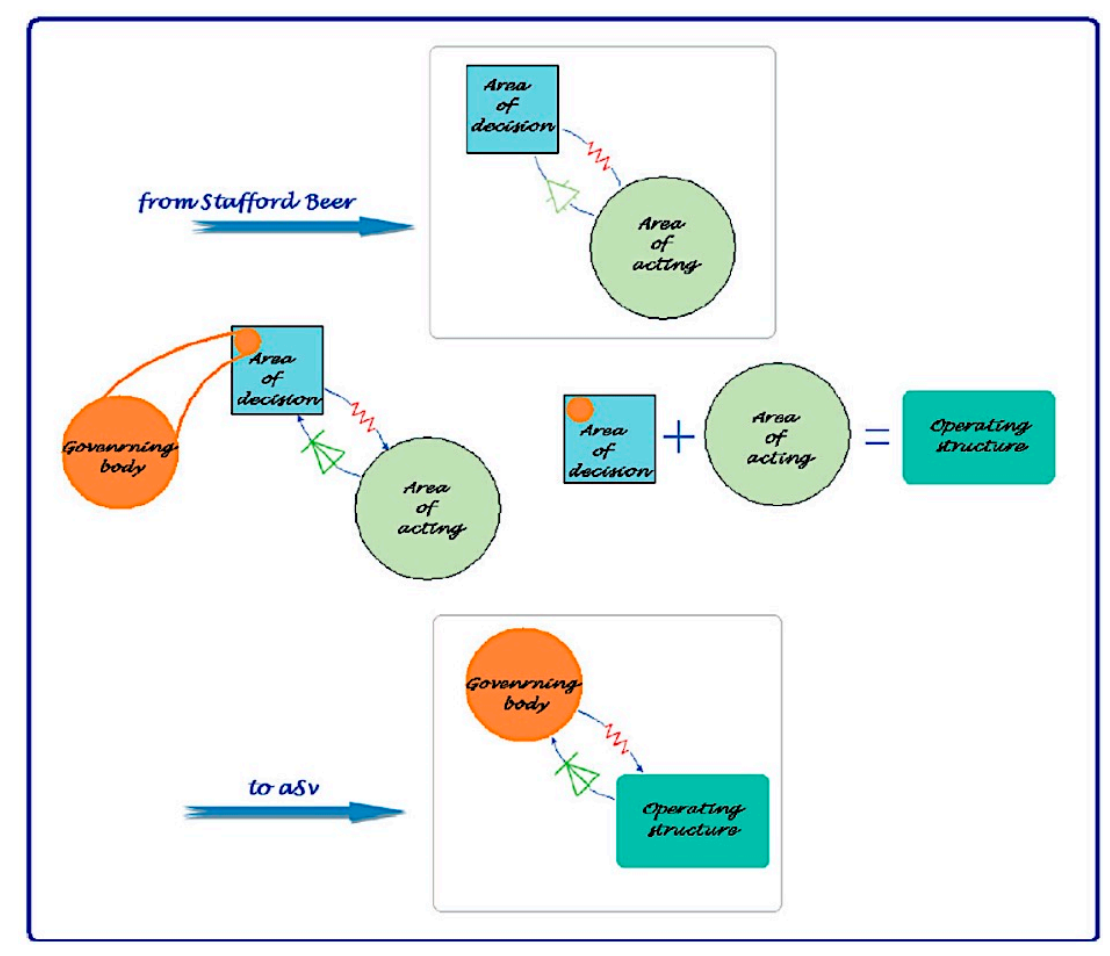

Figure 2. From Beer's viable system model to the viable systems approach. Source: www.asvsa.org.

According to this representation, the vSa identifies both a structural dimension-which is static, and considers the parts and the relationships that exist among them-and a systemic dimension that is dynamic and concerned with the identification of the interactions, while keeping into account the structural components themselves $[27,28]$. The clear distinction between potentiality and act, and therefore between structure and system, is definable as preparatory to the systemic paradigm. Already, Aristotle and the first Pythagoreans, in investigating the becoming and change of reality, identified the concepts of form and the substratum (material substance) of things.

These concepts are fundamental for understanding the concepts of structure (expression of a potentiality) and system (an expression of actuality), and of the relations between them. For Aristotle, becoming is characterized by the action of an efficient cause that, acting on the matter, gives it shape (informs it), thus making it suitable to specific necessities. From these conceptualizations, it is easy to detect the close analogy with the systemic concepts in which the matter (structure), through an efficient cause (the organizational scheme), is adequate to meet certain needs (the system). Therefore, in this perspective, the structure, which is also intended as a genotypic dimension, coincides with different semantic qualifications for which it is widely used. As an example, the concept of nation implies the presence of components that are connected with each other. The process dimension (phenotypic dimension), on the other hand, is studied through the notion of system. At the system level, the physical boundary no longer has a reason to exist; the function is compressed in a certain role, and above all, from the connections we move onto the concept of relationships. Once activated, these relationships produce the interactions between the components that allow the emergence of the system. 
Therefore, in this perspective, what matters is: firstly, the condition of the relationships, and secondly, that of the interactions, which the vSa qualifies on the basis of the concepts of consonance and resonance. Consonance represents the potential condition of compatibility and/or complementarity between interacting entities, while resonance represents the consequent effects of harmonic interactions between two or more systemic entities, and is related to the pre-existent condition of consonance. The role of the vSa's key concepts of consonance and resonance in orienting business behaviors is fundamental $[11,28]$. In fact, as said, the need of preserving viability conditions for a system is strictly linked to its ability to set up and develop consonant relationships with the various entities that define its context of reference. This ability is crucial when referring to territory governance, as this issue calls for the "openness" of the decision-making processes that consider the relevance of the interactions between the viable system and all the entities of a specific territory, and identifies the most appropriate path of governance.

In this case, governance is not hierarchical, but can be referred to the notion of panarchy. Based on the Greek god of nature, Pan, panarchy was coined to represent "nature's rules", in contrast to hierarchy, which indicates top-down control [29]. In this sense, we can expect a progressive shift to a notion of systems that is characterized by the collaboration of distinct systems that cooperate to achieve coordinated results, with the ability to access and share remote resources [30]. The transition from an isolated system that is deterministic and closed to a distributed one that is opened and potentially non-deterministic implies an exponential increase in complexity [31]. So, a new and more effective point of view emerges, with a wider and stronger solution to reach systems of systems, for which a global vision will be gained [32]. This global vision seeks to consider all of the elements and factors that contribute to the occurrence of each event, whether they are of a random, casual, or subjective nature. Each organization, then, takes on a broader role that leads in particular to deepening their skills in a systemic perspective, setting aside unilateral and partial views [33].

\subsection{Vsa for Territory Governance}

Therefore, the contribution of the vSa underlines the importance of relation (identified by the structural compatibility and defined by consonance) and interaction (identified by the system's dynamic and defined by resonance) rather than connection among actors. This shift is also important in terms of sustainability, as it calls for interaction and dynamism that overcome the only physical/monetary exchange, as it involves personal values and strong beliefs.

Thus, the need to integrate good management practices with sustainable behaviors, as difficult as it may seem, carries with it the possibility of obtaining positive results, especially in terms of virtuous territory governance.

Accordingly, the adoption of the viable systems approach (vSa) as a governance methodology allows the focus to be appropriately shifted from the parts to the whole. In fact, as previously said, through the lens of the vSa, the concept of sustainability becomes particularly relevant, and directs us towards a wider view that contemplates the perspectives of the various stakeholders.

In other words, we can say that in the long run, a firm is viable if it is sustainable, and that this could be the necessary condition for preserving the viability of a system, although it is not sufficient.

In fact, viability is the result of the strategic choices that, based on the ability of the decision maker to read the context and correctly interpret the system of laws, norms, and rules that constrain and limit the spectrum of possible actions, define the company's trajectories of sustainable development [28].

The paradigm of viability is thus enriched by valuable indications of conduct for the decision maker who, by including the assessment of sustainability in the definition of the strategy, increases the company's chances of survival. This, magnifying the company's viable capacities, activates a virtuous circle of sustainable development. Therefore, the commitment to the sustainability of the company translates into a higher probability of survival in the context in which it operates. This gives rise to a typically recursive link in which the commitment to the sustainability of the company increases its 
chances of survival through the survival of the context in which it operates, and recursively, that of the higher-level contexts in which, in turn, it is placed.

Thus, sustainability is the process activated by the viable system components of a broader, higher-level viable system (up to the broader and more inclusive vision of the environment), in the will to ensure its survival.

This means that the viable system, defined according to the vSa, will be sustainable if it is able to build consonant relationships and develop resonant interactions with all of the systemic entities with which it comes into contact within the specific context defined by its governing body. Accordingly, sustainability is defined as a process, and therefore, it is dynamic and changing according to the changing needs of the context and the actors present in it.

The vision of sustainability that is proposed herein, which, as said, is closely linked to the notion of systemic viability, considers the general environment a complex organization that includes a wide variety of dimensions defining the structure. When the structure is seen in its functioning and activation, we can observe systemic dynamics that are the results of the interweaving (which should be virtuous) of subjects, resources, and events into the economy, environment, and society. In this perspective, in order to characterize sustainability as the relevant dimension for guaranteeing systemic viability, the governing body of the organization must be able to understand the context, so as to dynamically determine the most appropriate strategy to be adopted, even if this leads to new (sustainable) configurations of the system. Thus, sustainability also becomes a fundamental indicator of intersystemic relationships that are capable of signaling when the limit of elasticity of a relationship has been exceeded; this means that it is strictly linked to the adaptability of the system in achieving its main purpose.

The simultaneous observation of phenomena from both a structural (static) perspective and a systemic (dynamic) perspective is one of the key elements that should be considered. In order to propose a rereading of sustainability through the vSa, given the need to define the perspective of observation, we can say that that the perspectives can define a sustainable set of relationships and activate sustainable interactions only when they are simultaneously considered.

The contribution of the vSa to sustainability allows the purpose of survival to be combined with a philosophy of governance for sustainability through the simultaneous observation of both the structural and the systemic dimensions of phenomena. This simultaneous contemplation of different perspectives through the methodological lens of the vSa can be useful for orienting decision-making processes towards sustainability, as we will illustrate in the following paragraph.

In order to outline the interpretive premises underlying this proposal, it is useful firstly to briefly focus on the concept of development. In the viable systems approach, with reference to the business organizations, the definition of the evolutionary trajectories of the system leads to a matrix of evolutionary options that distinguishes between growth and development. The growth actions will qualify the purpose of achieving a significant quantitative increase in the entity of the results achieved by the system, whereas the development operations are characterized by the achievement of significant improvements in the use of embedded capabilities.

This difference can be better explained by referring to the vSa structure-system dichotomy [27], according to which the decisions of the governing body can be distinguished between management decisions pertaining to the operating structure, and government decisions that relate to the system as a whole. This distinction, although derived from the one already proposed by Stafford Beer, highlights substantial differences compared to the previous model. In fact, this model, which distinguishes between "government" decisions and "management" decisions within the area of the decision as understood by Beer, recovers the significant distance that exists between the distinct phases of decision-making and problem-solving. In fact, the first ones are connected to government decisions, which is typical of emerging problems that are not related to consolidated cases. Instead, the second ones deal with usual problems that are already contemplated and solved. Consequently, after separating the decisions relating to management from the complex of decisions and merging 
them with the area of action, the reformulated viable system schematization finds the principle of isotropy (as established in the business economic literature) in the behavior of any organization that is expressed in areas of government decisions and operational activities. This formulation, which is as consistent as the one proposed by Beer, also recovers recent research on the functionality of the human brain. These studies have highlighted the possibility that, compared to the decision-making process, there are structural components that are dedicated to "deductive" rather than "inductive" processes, and are therefore also dedicated to phases of decision-making rather than problem-solving.

By adopting this distinction, the focus can shift from the static view of the components-which is intended as capability incorporated in the structure-to the dynamic view of the processes achievable by the system. Therefore, the focus can also shift to the "implementation" process; that is, to the effective employment of these capabilities.

Often, the definition of the government action could privilege a vision that is mainly structural, if not reductionist, and which inhibits the identification of the opportunities arising from the adoption of a systemic vision. Such an approach is generally attributed to the legacy of a "dominant" vision that is excessively focused on the parts rather than on the processes, and strongly influenced by the perception of the materiality of the objects. Instead, the above-mentioned "structure-system" perspective reveals a possible dichotomous view that can prevent capturing the intimate bond between the structure and the system. It can also prevent capturing the implications of the dynamics of the emersion of the system from the structure, making one necessary to the other. Without the structure, the system does not emerge, but the existence of the structure does not automatically lead to the emersion of the desired system.

For the peculiarities that will be highlighted below, in the governance of territory, a tendency to an excessively structural view is particularly evident: the definition and perception of the geographical, administrative boundaries of a territory often prevent the actors of the decision-making process from developing full awareness of the recursive link that connects the dynamics of the territory at the various levels of its organization, making the concept of borders irrelevant, if not misleading, from the systemic point of view.

These reflections also clarify another important aspect of the proposed framework for the governance of territory, which is related to the delimitation that is implied in the concept of the "local". Even here, the "structure-system" paradigm helps clarify how the same definition contained in the concept of the "local" may be declined both structurally and systemically. A territory, as well as a local area, can be structurally identified through locating the boundaries that physically and administratively delimit the considered area, and identifying the components that can be considered as incorporated within it. However, these boundaries systemically become evanescent, not only by including the external components in the structure and referring the incorporated capabilities to the extended structure, but also by opening the dynamics of the system to an unpredictable complex of interactions emerging from the set of processes that are systemically activated.

From a development perspective, this aspect is central, and leads to conceiving a systemic vision of a territorial government that is open to the potentialities that emerge from internal and external interaction processes.

\subsection{Territory as a Viable System: A Reference Model of the Governance of Development}

The investigation of the issues related to territorial development finds in the territory that is conceived as a viable system, and theorized in the strand of the viable systems approach studies, a good reference model for the definition of an appropriate and effective governance approach that is consistent with the outlined interpretative premises.

From the perspective of the viable systems approach, as highlighted before, any organization that is designed to fulfill a given purpose can be conceived as a viable systemic entity. It is now useful to clarify that the term "territorial governance" can be used to summarize both the references to the individual initiatives of development of a specific local system, and the overall synthesis of all of the 
possible systems organized within a specific territory. That said, in what follows, we will discuss the territorial governance in a sense that also includes the governance of specific development initiatives that have an impact on a territory, or that are realized in the interests of a territory. The interpretive assumption consists in holding that the results achieved by a specific initiative are always related to the context of the dynamics that develop both on the outside and on the inside of the observed system, by drawing a diagram with recursive interactions.

The viable system model of territory provides a representation that is useful for supporting governance decisions that are aimed at improving the chances of survival of the system, and enabling an assessment of project proposals for:

- $\quad$ the enhancement of the heritage of a geographical area;
- $\quad$ the development of a territorial vocation;
- $\quad$ the growing competitiveness of the territorial systems.

The characterization of territorial systems as viable systems can be observed both at the level of the governing body, and at the level of the operating structure. The peculiarities of the territorial systems are attributable to their composite, multi-subjective nature, as well as to the high articulation, if not fragmentation, of the decision-making entities. The peculiarity of the operating structure is identified in its multidimensional nature due to the wide variety that distinguishes it. At the same time, the governing body and operating structure form a systemic entity that is typically multi-stakeholder, given the variety of stakeholders and the viable dynamics of territory at which they are oriented. So, a territory that is intended to be a viable system qualifies a systemic entity that is typically multi-subjective, multidimensional, and multi-stakeholder [34,35].

Compared to government action that is aimed at territory development, the variety of subjects that are involved in or interested in the dynamics of territory determines a certain level of complication in the activity of governance, which is described with particular reference by the need to develop the consonance conditions of the context. In fact, the territorial system is characterized by the presence of components that belong to the specific territorial geographical area-such as natural, artistic, cultural, and structural components, as well as urban planning, infrastructure, etc. However, the territorial system is also characterized by systemic components. These systemic components include the enterprises, social organizations, individuals, entities, and institutions that have a fundamental and autonomous capacity to generate value. These systemic components also tend to project the predictions and subjective expectations, as a result of the pursuit of the better chance of survival in their territorial context of reference [36].

In fact, the typical mode of operation of the territorial organizations generally leads to the definition of agreements and collaborations with numerous other systemic entities. These entities are either present or not present in the territory, and become nodes that are capable of generating further physical, financial, cognitive, and human resources through the acquisition and sharing of knowledge). They can also generate the sharing of investments, the generation of distinctive competencies, the transfer of technology, the creation of complementarity in using the resources, the generation of relational capital, the reduction of the risk level, etc.

Essentially, in the territorial organizations, development is co-produced by the plurality of actors who are involved in the various initiatives and open to unpredictable development potentialities that the governing body must be able to intercept and exploit.

Each of the actors involved in development initiatives acts in a general environment, from which specific context of reference is subjectively extracted, according to the specific objectives pursued [37]. The opportunities for a comprehensive harmonization of interests can only be assessed in a unified vision of the concrete relational conditions between actors, as they are closely connected to the logic of the consultation and the principle of consensus. Due to the pluralistic nature of the players involved, the ability of a decision maker to govern the structure created by a specific initiative in a unified way is even more crucial, as it ensures adequate levels of consonance both at the intrasystemic and 
intersystemic levels. Thus, the capacity to develop the consonance of the context becomes fundamental: as it has been said, the governing body must be able to govern the whole of the progressive reorientations deriving from all of the viable systems that are referable to the same context.

All of this becomes fundamental, given the composite nature of the governing body of the territorial organizations, and its ability to unitarily direct the decision-making process and thus make an integration of resources possible. This is possible by ensuring an intimately compatible and coordinated extraction of multiple contexts results, while aiming at the satisfaction of a sufficiently coherent broad set of relevant suprasystems. In fact, according to the viable system perspective, the decision maker, in the search for options to increase the chances of the organization's survival, recognizes in the environment the systems that give the greatest possibilities of release the resources that necessary for its viable activity. The decision maker also evaluates the expectations (counterpart) that the identified system has with respect to the release of the resources, and, by adapting its decisions because of the conditioning deriving from taking the identified system into account, in fact inserts it in its context.

The system that is identified and included in the context is qualified as a suprasystem. The measurement of the conditioning capacity of each of the suprasystems is expressed in terms of relevance, which indicates the capacity that the external system has to condition the survival prospects of the viable system. In essence, the determination of the degree of relevance is the result of a value judgment that is formulated by the governing body with reference to the capabilities and probabilities of a suprasystem to be critical and influence its existential dynamics, and, therefore condition and guarantee the development of an intersystem relationship and, consequently, the pursuit of systemic purposes.

The importance of a value assertion, which refers to the evaluation of the relevance of a suprasystem, is based on the finding that the correct interpretation by the governing body of the potential for interaction that is consequent to the establishment of a relationship with a suprasystem, is that it can be a source of creation of value, competitive advantage, and therefore, improvement in the probability of survival of the system. Hence, the determination of the "degree of conditioning" of each suprasystem is a fundamental moment, as it involves the governing body's delineation of the feasible entrepreneurial ways that the viable system can improve its chances of survival in a context that is characterized by structural and systemic variety.

Thus, the governing body of the viable system, by filtering both the purposes and expectations of the suprasystems, has the role of designing the internal and, when possible, external changes.

However, this role needs a decision model that is able to allow, on the one hand, the identification of strategic paths through the definition of a structural change plan, and on the other, the choice of the types of relationships in order to improve the consonance and resonance of the interactions with the suprasystems.

\section{The Composite Nature of the Governing Body of the Territorial Organizations}

The multiplicity of roles that characterize the action of the territorial organizations, as said, refers to a typical multi-subjective configuration of the governing body, which is articulated as the possible decision-making functions and reproduced at different institutional levels of the territory. The vSa provides interpretive schemes that are useful for the representation and analysis of the dynamics of formation of the local systems through the identification of three logical levels of government [36]:

- The Authorizing Subject of the territory (A.S.), typically the Governor or the executive board, who is tasked with identifying the lines of action derived from the subjective perception of the environment. Through the subjective identification of specific vocations, this subjective perception extracts one or more contexts on which the attention of potential coordinating subjects can be focused;

- $\quad$ One or more Coordinating Subjects (C.S.), who are able to develop proposals within the different contexts identified by the A.S.; 
- One or more Proponent Subjects (P.S.), who are engaged in implementing the projects that are connected with the proposals formulated by the C.S.

The distinction of subjects and roles is not rigid. However, generally, the variety of territorial governance issues is such that it requires skills and competencies that are difficult to be present in a single subject. In addition, the role of the Authorizing Subject must necessarily be filled by an institutional subject, while the Coordinating Subject and Proponent Subject can be institutional or private entities, or even mixed organizations. Naturally, the lines of action identified by the Authorizing Subject are developed within a context defined by another decision maker (the pre-authorizing subject), which could refer to other decision-making subjects of an even higher level. Therefore, the different levels are structured according to a typically recursive scheme [38], which is also considered in the vSa [37].

The process of defining a local development system involves decision makers engaged in a planning activity, which requires an orderly and consistent composition of choices of different degrees that are carried out by different subjects. The model proposed to support the action of government, which is typically of a multi-level and modular nature, reproduces the project cycle that is represented by the conceptual matrix of the vSa (Figure 3), under which, on the basis of targets set by the governing body, one of the possible systems of development emerges from an objective and shared structure (a territorial area).

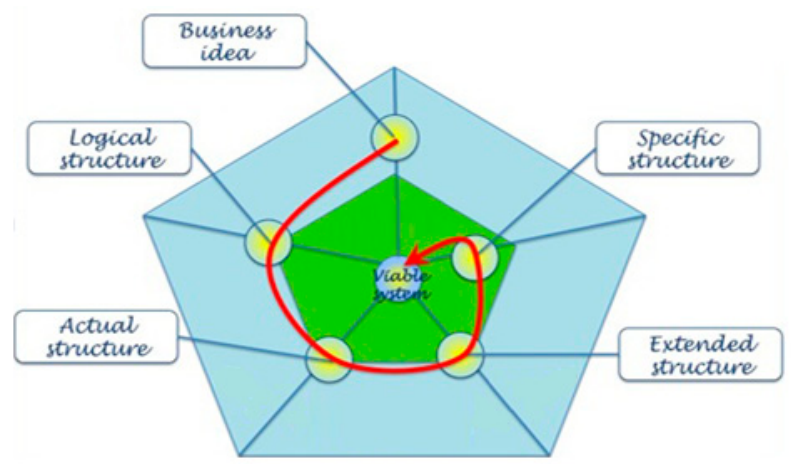

Figure 3. The conceptual matrix. Source: www.asvsa.org.

Particularly:

- A decision-maker subject (A.S.) configures a logical structure, such as the representation of the resources available in a territorial environment, and the priorities for their valorization or permanence;

- $\quad$ One or more decision-maker subjects (C.S.), within the contexts identified by the A.S., specifies the necessary capabilities, establishing a certain balance among internal enhanced resources. These resources are especially constituted and obtained from the outside, thus defining the extended structure;

- $\quad$ One or more decision-maker subjects (P.S.) contribute to the definition of the specific structure of a territory through the creation of projects that are consistent and instrumental to the above-mentioned directives.

The multi-subjective configuration of the governing body proposed herein well represents the reality of local development government organizations, which are generally distinguished by a state and a territorial institutional subject (that assumes both the role of the authorizing subject and the role of the coordinator, or even the role of the proposing subject). These organizations are also distinguished by a variety of proposing subjects who are also private, and may be involved in the initiative of development. This involvement is typically through adopting network and project organizational solutions on the basis of juridical regulated agreements. 


\subsection{From the Environment to the Context: Identifying Paths of Development for Territorial Systems}

Given the wide articulation of the systemic levels observed in relation to territory, the outlined distinction between environment and context is particularly relevant.

Therefore, in what follows, we will explain more precisely the implications of this distinction in relation to systemic organizations related to territory.

As has been introduced before, the environment qualifies a set of objects that are independent from a process of perception that is attributable to a single observing subject. The logical shift from environment to context is the outcome of the subjective cognitive process of a specific observer that extracts from the environment objects that are associated on the basis of a criterion of differentiation and a specific purpose. In relation to the territory, the environment is a complex of resources with a different nature, which is related to its geographical dimensions. The context, instead, is the product of an initiative that involves and makes a subset of these resources effectively interact through combining them with external resources and/or new internal resources. Such an initiative should be characterized by a long-term sustainability (opportunity and feasibility), and by the complementarity with other contexts that are implemented in the territory (compatibility).

Starting from a more general territorial environment, the extraction of the contexts implies a selection process. The criteria of this process that derive from these lines of development have been identified as follows:

- policies of internationalization and the diffusion of local production derived from a qualified sectorial expertise;

- policies to attract investors, companies, and citizens from other external geographical areas;

- policies to encourage incoming tourist flows to one geographic area;

- $\quad$ innovative policies that support governance, programming activities, verification, and evaluation;

- $\quad$ policies aimed at learning in the reproduction of virtuous circles at the territorial level;

- $\quad$ policies aimed at skills that are able to link together different policies, mobilize a plurality of actors, and build territorial socioeconomic partnerships;

- $\quad$ strategic creation of new ideas and the improvement of knowledge about existing resources that are either inefficiently exploited or not utilized at all.

The concept of the context is included in the synthesis effort made by the decision makers when they select the possible lines of action to promote development in a particular environment. The governing body of the territory, on the basis of a subjective assessment, identifies in the environment those references (suprasystems) towards which it considers that the maximum attention should be addressed. The governing body interprets the suprasystems' needs, derives their objectives, and outlines the strategy for achieving them.

However, as it has been illustrated, in the emergence of complex and active relationships, the viable system includes not only components that are already present in the context, but also components that go far beyond the environment itself. These dynamically new components are included because structural boundaries become evanescent with the emergence of the system [39-42]. This should encourage the governing body to develop an awareness of the systemic dimensions of the territory (as well as any initiative organized for its development), overcoming the limits of the structural perspective. The outdated structural perspective consists of a 'dominant' perspective that was conditioned by the perception of the physical and material characters of the components of the territory, on which it often collapses its vision.

The environmental and contextual representations fail to capture the unpredictable set of interactions that can be systemically activated. This is particularly true in the case of territorial organization, which, as repeatedly stated, is characterized by a high variety of components and subjects that act and operate within a specific territory.

Therefore, the territorial government takes the form of action, which is implemented in most of the decision-making levels and is oriented towards: 
- $\quad$ enhancing the components present in a specific area;

- coordinating the behavior of systemic components that are directly and indirectly involved in the development processes of the specific territorial system;

- $\quad$ attracting new resources and, consequently, new components;

- $\quad$ inducing dyadic and contextual consonance.

The previous points that describe the action of the government, in systemic terms, are interpreted as the search for a shared development pursuit by setting certain priorities that are aimed at further increasing the chances of survival of the system against global competition. Subsequently, government action tends to encourage the coordination, involvement, and participation of the systemic components to put the conditions for the emergence of the consonance of a specific context into place. The purposes include the satisfaction of the public of reference, the development of further competences between components that already exist and are related to the system, and the attraction of new components.

The consonance creates the relational conditions of mutual attraction, aligning the strategies of the different players toward common goals. The capacity of attraction and the qualification of the components is, on one hand, the expression of the opening of the system, and, secondly, the expression of its elasticity and flexibility towards adaptation needs. On the other hand, the competitiveness, as an opposing force, acts to affirm the distinctiveness. This distinctiveness was firstly developed by enhancing the existing resources, which were then consolidated with the influx of new resources, until the system reaches a state of equilibrium that is characterized by the proper balance of different needs.

\subsection{The Selection of the Possible Lines of Action to Promote Development}

In the governance of the development of a local system, the decision makers have the task of stimulating the behaviors of the different components of the system by means of a coherent strategic plan. Such a strategic plan encourages convergence towards common objectives of development, and therefore, towards a common viable system from each single actor, valuing the contribution of each of them towards the action of the system.

The conceptual assumption at the base of the model in support of the decision-making process proposed here, is the awareness that the action of the territorial government depends on the ability of the governance (often different decision makers in action) to exploit the potential and the vocations related to a specific area. The capabilities and the vocations of the territory represent factors of differentiation and attraction to which the enhancement of the territory itself is connected, whether the vocations are productive, touristic, historical, or artistic.

The possibility of establishing exchange relations with the external areas should be associated with these factors, in order to obtain the resources (investments, tourists, agreements, and collaborations with other territories) that are useful for the creation of an instrumental competitive advantage towards the pursuit of development objectives.

As summarized in Table 1, the phase in which the authorizing subject identifies a specific set of resources in the logical structure is particularly significant. This set of resources conditions the definition of the evolutionary paths, i.e., the definition of the extended structure. In addition to ensuring the survival of the emerging system, this extended structure allows the focus of activities and processes toward the development trajectory. 
Table 1. Key elements for territory development according to the viable systems approach (vSa).

\begin{tabular}{ccc}
\hline Logical Level of Government & Specified Elements of Equipment & Type of Structure \\
\hline Authorizing Subject (A.S.) & $\begin{array}{c}\text { Resources: Identification and classification of territorial resources that } \\
\text { are to be taken into consideration }\end{array}$ & Logical structure \\
\hline Coordinating Subject (C.S.) & $\begin{array}{c}\text { Capacity: Identification of all of the components and the internal and } \\
\text { external relations that are capable of expressing the identified resources }\end{array}$ & Extended structure \\
\hline Proponent Subject (P.S.) & $\begin{array}{l}\text { Competence: Identification of appropriate interactions between the } \\
\text { components that are capable of performing activities and processes }\end{array}$ & Specific structure \\
\hline Source: [36], p. 256. &
\end{tabular}

At this point in the analysis, it is important to emphasize that the process of extraction of contexts from the environment recursively occurs at all of the examined levels of government, leading to a situation as the one depicted in Figure 4.

In Figure 4, starting from a reference environment, which is nothing more than a context defined by a higher-level decision maker subject, the Authorizing Subject, by extracting a context through the identification and classification of the resources that are considered necessary for the achievement of a certain purpose, defines the logical structure.

At the subsequent level, one or more Coordinating Subjects extract a context from the environment that is defined by the authorizing subject, identify the extended structure, and define all of the components and the internal or external relations that are capable of exploiting the identified resources.

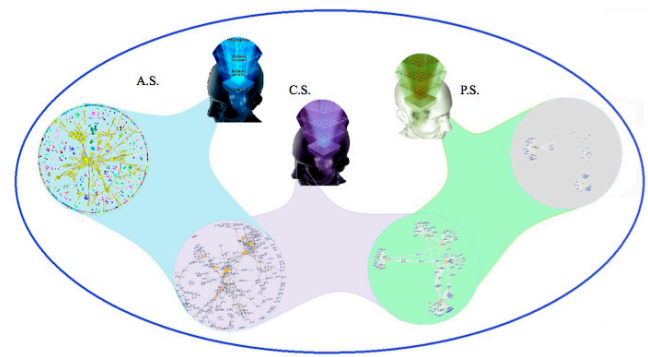

Figure 4. The different territorial contexts emerging from the different subjects. Source: www.asvsa.org.

In a further next level, one or more proponent subjects extract a context from the environment that is defined by the coordinating subjects, defining their specific structure by developing patterns of interactions between the components that are capable of performing the activities and the planned processes.

The designed scheme indicates the definition of the extended structure as a central moment of the territorial decision-making process; therefore, any of the entities organized for local development can be subjectively represented through an extended structure, as an expression of the perception of the constraints and, at the same time, of the opportunities of development of a given territorial area.

Thus, the extended structure becomes an expression of a process of resource selection, which is carried out by a decision maker in relation to a development purpose that is strictly related to the specific structural potentialities of a territory. By each of the extended structures, then, a specific structure can emerge containing a plurality of paths of development that are more or less coordinated between them.

The assessment of the components to be included in the different specific structures should be carried out at multiple levels. Once the stability of the individual and relational capabilities of the components are defined from a structural point of view, this assessment ought to allow the formulation of a systemic synthesis judgment of the components' ability to contribute to the demanded consonance of the context.

In essence, the steps will be related to the assessment of:

- a value of the components (resource, capacity) that is based both on the criterion of compliance, with the requirements expected by the decision maker, and on the availability in the territory. 
Such an assessment should assign priority firstly to the existing components, then to those that are non-existing but achievable, and, finally, to the ones that are recoverable from the outside;

- $\quad$ a value of the synthesis of the capacity of the components considered together. This valuation process must also be transposed to the analysis of the value of the relationships between the components, in order to measure the systemic potential that is present in the specific structure and, therefore, the possible emergence of resonance;

- a subjective value of the components, which is inherent to the appreciation of the current relevance of the individual components, or rather the ability to influence the choices of the decision maker, in relation to different possible identifiable specific structures. Therefore, the objective is to evaluate the contribution of each component in the pursuit of the objectives of the territorial system.

Evidently, the articulation of the assessment involves a certain complication of the decision-making process, emphasizing the need to have available schemes that allow a simultaneous evaluation of the different variables to be considered for selection.

\section{Personal Contributions and Final Remarks}

From the developed considerations, it appears (although not in explicit terms) that the different components in a context of reference, such as a territory, can give rise to a viable system. This occurs through the subjectively mediated composition of the different value categories, so as to allow the concretization of a systemic dynamics that underlines the importance of considering a variety of different perspectives [43]. The theoretical model presented herein can be intended as a conceptual framework that may be further developed through the analysis of real cases and empirical verifications. The contribution of the proposed framework can be exploited alongside consolidated management models both by institutional actors who see the entire territory as a viable system, and by entrepreneurs who see in the territory a fertile context of action from which to draw different paths of development opportunities in a harmonious purpose-based approach and a shared perspective of sustainability.

Although the framework is theoretical, the originality of the paper lies in proposing a synthesis model for a synergic development of the territory that gathers together organizational, contextual, and environmental perspectives, promoting sustainability in territory government processes.

The "social and economic" interests of the system as a whole do not always correspond to an immediate increase in the "economic and social" interests of a single part. Just like any field of research, this area of study cannot be considered distant and different from others fields of human knowledge, because by taking a closer look, all of them are subsets of a greater whole that is characterized as a dynamic system of human activities.

Current thinking on sustainability and territory tends toward a holistic concept in which true explicit reason is found, even though, for necessity of representation, a traditional reductionist expression is usually preferred. It is important to think about the typical pattern of the triple bottom line, as described above, where the different social, economic, and environmental areas should contribute to the recovery of a 'sustainable intersection', without considering the dynamic of the different components that act in each of the three dimensions.

This work tries to help overcome the traditional economic approach. The latter assigns to the actors a condition of omniscience, or otherwise gives them an impossible knowledge of the relevant data. However, the reality is different. Individual actors know little. There is a division of knowledge within society. The cooperation between the different actors, which is made possible by the reference context, represents a valid model of the mobilization of knowledge that no individual possesses in its totality. This is because knowledge is dispersed in the social system, and cannot be centralized by any authority.

In fact, the vision that is imposed today looks forward and considers the fact that unilateral decisions have influences on the community. If this was not considered, the entire system would undergo a crisis. The present study should not fail to look at the future by recovering the human dimension, which is the essence of our existence, and that of future generations. 
The debate around our responsibility toward future generations has become more and more dense and interesting, as certainties about the development model based on the technological enslavement of nature have vanished, and modernity has given way to a vision of history that is disenchanted and perplexed. In this direction, concepts such as that one of the Anthropocene have become particularly relevant [44]. Starting from these considerations, we have tried to go to the roots of the problem, which is not just about the survival of viable systems, but also about the unity of species and the dignity of their existence. Between hope and despair, the principle of responsibility therefore represents an alternative way that is able to combine ethics and realism in a unitary model.

Acknowledgments: Authors used their University funds for covering the costs to publish in open access.

Author Contributions: This paper is the result of common reflections. Sergio Barile wrote Sections 1 and 4; Bernardino Quattrociocchi wrote Section 2; Mario Calabrese wrote Sections 3.4 and 3.5; Francesca Iandolo wrote Sections 3.1-3.3

Conflicts of Interest: The authors declare no conflict of interest.

\section{References}

1. Barile, S.; Polese, F.; Calabrese, M.; Iandolo, F.; Carrubbo, L. A theoretical framework for measuring value creation based on Viable Systems Approach (VSA). In Contributions to Theoretical and Practical Advances in Management, A Viable Systems Approach (vSa); International Printing Srl: Avellino, Italy, 2013; ISBN 978-88-548-6082-7.

2. Brundtland Commission. Our Common Future; Oxford University Press: Oxford, UK, 1987.

3. Dréo, J. "Sustainable Development". 2006. Available online: http://commons.wikimedia.org/wiki/File: Sustainable_development.svg (accessed on 11 December 2017).

4. Elkington, J. Cannibals with Forks. The Triple Bottom Line of 21st Century Business; Capstone Publishing: Oxford, UK, 1997.

5. Elkington, J.; Fennell, S. Partners for sustainability. Greener Manag. Int. 1998, 24, 48-60.

6. Daly, H. Beyond Growth, the Economics of Sustainable Development; Beacon Press: Boston, MA, USA, 1996.

7. Robèrt, K.H.; Anderson, R. The Natural Step Story: Seeding a Quiet Revolution; New Society Publishers: Gabriola Island, BC, USA, 2002.

8. CLEI-Local Governments for Sustainability. Available online: http://www.iclei.org/ (accessed on 11 December 2017).

9. The United Nations Educational, Scientific and Cultural Organization (UNESCO). Universal Declaration on Cultural Diversity; The United Nations Educational, Scientific and Cultural Organization: London, UK, 2001.

10. Barile, S.; Carrubbo, L.; Iandolo, F.; Caputo, F. From ego to eco in B2B relationships. J. Bus. Mark. Manag. 2013, 6, 228-253.

11. Barile, S.; Saviano, M.; Iandolo, F.; Calabrese, M. The viable systems approach and its contribution to the analysis of sustainable business behaviors. Syst. Res. Behav. Sci. 2014, 31, 683-695. [CrossRef]

12. Espinosa, A.; Harnden, R.; Walker, J. A complexity approach to sustainability-Stafford Beer revisited. Eur. J. Oper. Res. 2008, 187, 636-651. [CrossRef]

13. Barile, S. L'impresa Come Sistema, 2nd ed.; Giappichelli: Torino, Italy, 2008.

14. Barile, S. Management Sistemico Vitale; Giappichelli: Torino, Italy, 2009.

15. Golinelli, G.M. Viable Systems Approach. Governing Business Dynamics; Cedam: Padua, Italy, 2010.

16. Beer, S. Brain of the Firm: A Development in Management Cybernetics; Herder and Herder: New York, NY, USA, 1972.

17. Von Bertallanfy, L. General System Theory. Foundations, Development, Applications; Penguin University Books: New York, NY, USA, 1968.

18. Ashby, W.R. An Introduction to Cybernetics; Methuen: London, UK, 1956.

19. Ashby, W.R. The mechanism of habituation. In Proceedings of the Symposium on Mechanization of Thought Processes, Teddington, UK, 24-27 November 1958; Volume 1.

20. Bateson, G. Steps to an Ecology of Mind: Collected Essays in Anthropology, Psychiatry, Evolution, and Epistemology; University of Chicago Press: Chicago, IL, USA, 1972.

21. Bateson, G. Mind and Nature: A Necessary Unity; Dutton: New York, NY, USA, 1979; pp. 98-100. 
22. Maturana, H.R.; Varela, F.J.; Beer, S. Autopoietic Systems: A Characterization of the Living Organization; Biological Computer Laboratory, University of Illinois: Champaign, IL, USA, 1975.

23. Von Foerster, H. Observing Systems; Intersystems Publications: Seaside, CA, USA, 1984.

24. Watzlawick, P.; Weakland, J.H.; Fisch, R. Change: Principles of Problem Formation and Problem Resolution; WW Norton: New York, NY, USA, 1974.

25. Barile, S.; Calabrese, M. A new frontier in consulting: The (vsa) consulcube. In Contributions to Theoretical and Practical Advances in Management. A Viable Systems Approach; International Printing Srl: Avellino, Italy, 2011; pp. 245-262.

26. Espejo, R.; Harnden, R. (Eds.) The Viable System Model: Interpretations and Applications of Stafford Beer's VSM; Wiley: Chichester, UK, 1989.

27. Barile, S.; Saviano, M. Foundations of systems thinking: The structure-system paradigm. In Contributions to Theoretical and Practical Advances in Management. A Viable Systems Approach (VSA); International Printing: Avellino, Italy, 2011; pp. 1-25.

28. Carrubbo, L.; Iandolo, F.; Pitardi, V.; Calabrese, M. The viable systems approach for CAS survival: How to change and adapt through fitting process. J. Serv. Theory Pract. 2017, 27, 1006-1023. [CrossRef]

29. Holling, C.S.; Gunderson, L.H.; Peterson, G.D. Sustainability and panarchies. In Panarchy: Understanding Transformations in Human and Natural Systems; Island Press: Washington, DC, USA, 2002; pp. 63-102.

30. Ostrom, E. Governing the Commons: The Evolution of Institutions for Collective Action. The Political Economy of Institutions and Decisions; Cambridge Univeristy Press: Cambridge, UK, 1990.

31. Türke, R.E. Governance: Systemic Foundation and Framework; Springer Science \& Business Media: Berlin, Germany, 2008.

32. Barile, S.; Simone, C.; Calabrese, M. The economies (and diseconomies) of distributed technologies: The increasing tension among hierarchy and p2p. Kybernetes 2017, 46, 767-785. [CrossRef]

33. Schwaninger, M. Organizing for sustainability: A cybernetic concept for sustainable renewal. Kybernetes 2015, 44, 935-954. [CrossRef]

34. Freeman, R.E. Strategic Management. A Stakeholder Approach; Pitman: London, UK, 1984.

35. Donaldson, T.; Preston, L. The stakeholder theory of the corporation: Concepts, evidence, and implications. Acad. Manag. Rev. 1995, 20, 65-91.

36. Barile, S.; Golinelli, C.M. Modalità e limiti dell'azione di governo del territorio in ottica sistemica. In L'impresa Come Sistema. Contributi Sull'approccio Sistemico Vitale (ASV); Barile, S., Ed.; Giappichelli: Torino, Italy, 2008; pp. 243-268.

37. Barile, S. L'approccio sistemico vitale per lo sviluppo del territorio. Sinerg. Ital. J. Manag. 2011, 84, 47-87.

38. Beer, S. Diagnosing the System for Organizations; John Wiley: London, UK; New York, NY, USA, 1985.

39. Compagnucci, F. 'Le Economie Di Agglomerazione Urbana: Dai Distretti Industriali Alle Città'. In Reti D'imprese e Territorio. Tra Vincoli e Nuove Opportunità Dopo la Crisi; Zazzaro, A., Ed.; il Mulino: Bologna, Italy, 2010.

40. Fourdrignier, M. Dynamiques associatives et transformations des territoires. Manag. Avenir 2010, 10, $296-312$. [CrossRef]

41. François, H.; Hirczak, M.; Senil, N. Territoire et patrimoine: La co-construction d'une dynamique et de ses ressources. Revue d'Économie Régionale E Urbaine 2006, 5, 683-700.

42. Maillat, D. Milieux innovateurs at dynamique territoriale. In Économie Industrielle Et Économie Spatiale; Torre, A., Ed.; Economica: Paris, France, 1995; pp. 211-231.

43. Calabrese, M.; Iandolo, F.; Bilotta, A. 'From Requisite Variety to Information Variety through the Information theory the management of viable systems'. In Service Dominant Logic, Network \& Systems Theory and Service Science; Giannini: Napoli, Italy, 2011; ISBN 9788874315253.

44. Ison, R.; Shelley, M. Governing in the Anthropocene: Contributions from Systems Thinking in Practice. Syst. Res. Behav. Sci. 2016, 33, 589-594. [CrossRef]

(C) 2018 by the authors. Licensee MDPI, Basel, Switzerland. This article is an open access article distributed under the terms and conditions of the Creative Commons Attribution (CC BY) license (http:/ / creativecommons.org/licenses/by/4.0/). 